\title{
Patterns of abundance for Calanus and smaller copepods in the North Sea: time series decomposition of two CPR data sets
}

\author{
N. Broekhuizen, E. McKenzie \\ Dept of Statistics \& Modelling Science, University of Strathclyde, 26 Richmond St., Glasgow G1 1XH, United Kingdom
}

\begin{abstract}
We present a time series analysis of 34 yr of continuous plankton recorder (CPR) data for 2 taxa: 'total small copepods' and Calanus copepodite stages 5 and 6 in the North Sea. Each was resolved into spatial averages over areas which correspond to the hydrographic regimes of the North Sea as defined by ICES. An iterative method which enables reliable determination of the long-term trends, mean annual cycles and confidence bounds for the monthly means is presented. We find that a purely time-dependent (i.e. trend plus seasonality) model can explain in excess of $70 \%$ of the variance in the (log-transformed) data. Nonetheless, the correlation structure in the residuals is indicative of the additional influence of past abundances upon subsequent dynamics. The residuals of many of the adjacent regions within the North Sea exhibit significant cross correlations at lag zero. This suggests that stochastic events can influence zooplankton dynamics over very large areas. We found no evidence that the zooplankton dynamics in up-current regions drive the dynamics of their downstream neighbours. In contrast, hydrographically similar regions tend to share a common seasonal dynamic even when they are not adjacent.
\end{abstract}

KEY WORDS: CPR data Time series analysis of spatially resolved data Trend - Seasonal cycle . Autocorrelation C Cross-correlation

\section{INTRODUCTION}

The Continuous Plankton Recorder (CPR) Survey provides one of the longest running and spatially most extensive of ecological time series. It has yielded valuable insights into the distribution of a wide variety of planktonic organisms and some indications of the physical processes which influence their abundance (e.g. Taylor et al. 1992). Nonetheless, much of the treatment of the data has been qualitative and there has been little rigorous examination of the statistical properties of the time series. In this paper we present the results of a basic decomposition of regional time series for 'total small copepods' and copepodite stages 5 and 6 of the genus Calanus into long-term trend, seasonal pattern and random components. The first 2 of these components yield important information about the interplay between the environment and life-history strategies. The third component allows us to draw inferences about spatio- temporal relationships in the 2 copepod taxa which we consider.

Robinson \& Hunt (1985) present a preliminary analysis of a small part of the CPR data in relation to the underlying hydrography of the North Sea; however, the majority of analyses of the CPR data have aggregated the data across space with little regard to the North Sea's hydrography. This is despite the belief that local hydrography has a great influence upon zooplankton dynamics. We have followed the example of Robinson \& Hunt (1985) by aggregating the CPR data across space in a manner which is consistent with the underlying hydrography and bathymetry of the North Sea (ICES 1983) (see Fig. 1). By doing so, we hope to overcome the problems arising from attempting to analyse the very noisy data at the finest possible scale ( $1^{\circ}$ latitude by $1^{\circ}$ longitude) without losing our ability to detect any influence of hydrography upon local dynamics, as is the case when data are aggregated up to larger scales such as the 'default four region classifi- 
cation' (i.e. the boxes C1, C2, D1, and D2 of Colebrook 1975 ) or the sub-basin scale used in Aebischer et al. (1990).

We use 34 yr of the CPR data to address several questions about the dynamics of 2 of the most common zooplankton taxa in the North Sea. We first ask whether the long-term decline and subsequent recovery of the North Sea's copepod community (reported by several authors; e.g. Aebischer et al. 1990) was a uniform event across the entire basin. Equally important, how large was this decline in comparison with the intra-annual changes in abundance? Many authors have presented 'mean seasonal cycles' for the copepoda in the North Sea, but they appear to have disregarded the possibility that strong long-term trends and seasonal biases in the distribution of either zeroes or missing values may render these figures unreliable. In addition, the monthly means are always presented without associated confidence intervals, rendering it difficult to judge how regular the seasonal cycle is. We suggest an iterative method of estimating the seasonal dynamic which minimises the bias arising from trend and seasonal sampling errors in the time series. In most regions, we obtain a remarkably good estimate of what the 'mean seasonal cycle' is, though year to year variation is often considerable. Finally, we ask whether there is any evidence of residual dynamic left in the data once long-term trend and the seasonal cycle have been removed.

In our discussion we address the question of whether the dynamics in the various regions of the North Sea are correlated in a manner which is consistent with the view that immigration/emigration processes driven by gross water circulation patterns play a major role in determining local dynamics.

\section{NORTH SEA HYDROGRAPHY AND BIOLOGY}

Hydrographically, the North Sea may be subdivided into several relatively distinct regions although there is an overall anticlockwise cycle of water movement (Lee \& Ramster 1981, ICES 1983, Turrell 1992). Almost all the water entering the North Sea eventually leaves by way of a surface current which flows northward past the Norwegian coast. Circulation patterns will be discussed in relation to the box structure illustrated in Fig. 1 which is based upon one proposed by ICES (1983). Oceanic water spills into the North Sea over the northern boundary of box 1, however the overspill is comparatively weak, and once within box 1 water circulation is highly variable, and wind driven. A mix of oceanic and coastal water arising in the Irish Sea and from Scotland's west coast enters the North Sea by way of the Fair Isle Current which passes between the Orkney \& Shetland Isles

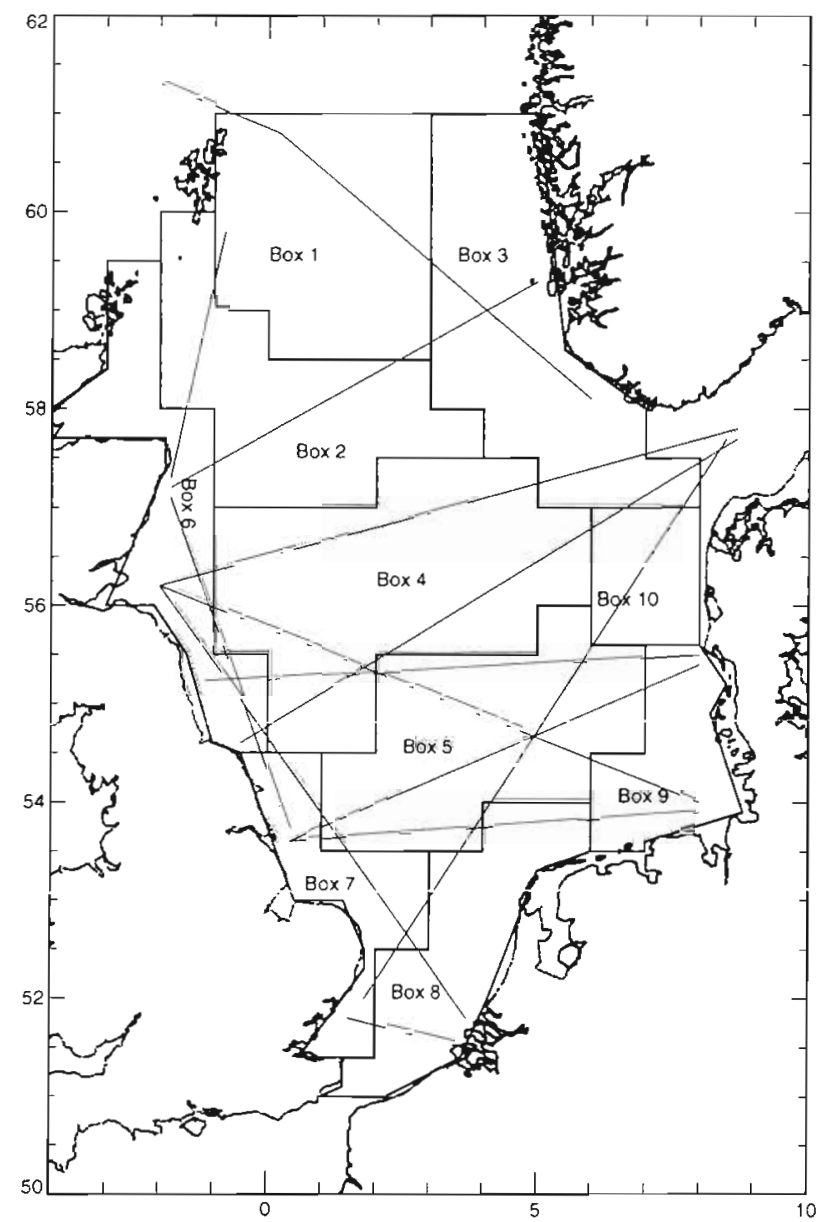

Fig. 1. The 10 hydrographic regions across which the continuous plankton recorder (CPR) data have been averaged, together with approximate indications of the longer running CPR tow routes. From time to time new routes have been introduced, or old routes dropped

to the northeast of Scotland. Most of this water sweeps through box 2 and eventually into the surface regions of box 3 , the rest passes down the eastern coast of Scotland (passing to the right of the relatively closed recirculation pattern formed in the Moray Firth $\left(58^{\circ} \mathrm{N}, 3.5^{\circ} \mathrm{W}\right)$. Most of this south-flowing water sweeps eastward into box 5 , but a small fraction passes further south into box 7 . Water entering the North Sea through the Dover Straits produces a strong current which flows up the Belgian and Dutch coasts through box 8 , the eastern part of box 5 and into box 3 via box 10. The German Bight area (box 9) is largely bypassed by this current and forms an isolated recirculation system of its own. Water circulation patterns in the central North Sea (boxes 4 and 5) are primarily wind driven. There is, however, a gradual northeastward movement resulting from entrainment by the continental-coastal current arising from the English Channel. 
Thermal stratification of the water column during summer is an important feature of the northern and central regions of the North Sea. In general, stratification first begins in the most northerly regions and spreads southward. Stratification in the central regions of the North Sea (boxes 4 and 5) is comparatively weak and is often temporarily broken by storm events.

On the basis of the zooplankton species to be found, Williams et al. (1993) divide the North Sea into northwestern and southeastern sectors. The northwestern sector is dominated by species characteristic of 'intermediate waters', notably Calanus finmarchicus which can make up $80 \%$ of the copepod biomass in the spring (Williams \& Lindley 1980). The latter sector harbours a broad range of neritic species such as Temora longicornis and Acartia clausi. It is not dominated by any one species.

Fransz et al. (1991) give a general description of the regional variation in the shape of the seasonal cycle and argue that there is (weak) evidence for a trend towards later and more gradual spring increases in copepod numbers in the southeastern North Sea while the amplitude of the seasonal cycle is suggested to be greatest in the northwestern parts of the North Sea. The early, rapid rise in copepod numbers in the north is strongly correlated with the spring phytoplankton bloom which appears to be triggered by the onset of thermal stratification (Colebrook 1979, Hays et al. 1994). Further south, stratification begins later, if at all. This, together with the fact that many of the southern species continue to graze the phytoplankton throughout the winter, delays and slows the spring phytoplankton bloom and consequently, the zooplankton growth. The amplitude of the seasonal cycle is probably smaller in the south because many southern species continue to feed and reproduce throughout the year while the northern species tend to migrate into deep water and enter a torpid period during winter.

\section{THE CPR DATA}

The CPR database is managed by the Sir Alister Hardy Foundation and we are pleased to acknowledge their effort in assembling the data in the format which we required. The CPR survey is described in detail in a various papers (e.g. Edinburgh Oceanographic Laboratory 1973) and the reader is referred to these for further details. Though zooplankton from many tens of taxa are recorded in the survey, only a few are sufficiently abundant to appear frequently in the survey and we restrict our analysis to just 2 of these groups: 'Calanus copepodite stages 5 and 6 ' (henceforth referred to as Calanus) and 'total small copepods' (henceforth, small copepods), this latter class includes the juvenile and adult stages of most copepod species but excludes the older stages of some of the larger species such as Pareuchaeta norvegica. It includes the smaller stages of Calanus but excludes Calanus copepodite stages 5 and 6 .

Within the CPR database tow data is recorded on a $0.5^{\circ}$ longitude by $1^{\circ}$ latitude basis. The monthly scores for each of these grid points were aggregated to provide monthly spatial averages for each of the 10 regions indicated in Fig. 1 over the period 1958 to 1991 inclusive. Nonetheless, it is important to remember that the data for each box come from 1 or more CPR tow routes and that these represent linear samples of a 2-dimensional area. Thus, even where there is more than 1 route crossing a box, the coverage is neither randomly, nor evenly distributed throughout the box. The main CPR routes for the period 1958 to 1991 are displayed in Fig. 1.

The underlying population dynamic processes of reproduction are multiplicative, as is emigration (advection of water will take a proportion of the local population with it). Advection of water into a region will carry in a quantity of zooplankton which is independent of the local zooplankton biomass. This is therefore an additive process. Nonetheless, since 3 of the 4 underlying dynamical processes are multiplicative, it is not surprising to find that the data are approximately log-normally distributed.

The data were log-transformed to normalise the error structure. This requires that zeros be treated as a special case, and we have chosen that they be excluded and treated as missing values. We prefer this procedure over the more commonly used $\log (1+x)$ transformation because the latter fails to normalise the error distribution when zeros are common in the data All analyses were based upon these (natural) logtransformed counts. Table 1 indicates how many missing, zero and non-zero scores there are in each of the time series. The possibility of introducing bias by

Table 1 Number of occurrences of missing values, zero and non-zero counts in each time series

\begin{tabular}{|c|c|c|c|c|c|c|}
\hline \multirow{3}{*}{$\begin{array}{c}\text { Region } \\
\frac{1}{1}\end{array}$} & \multicolumn{3}{|c|}{ Small copepods } & \multirow{2}{*}{\multicolumn{3}{|c|}{$\begin{array}{c}\text { Calanus } \\
\text { Missing Zero Non-zero }\end{array}$}} \\
\hline & Missing & Zero & on-zero & & & \\
\hline & 170 & 14 & 224 & 170 & 4 & 234 \\
\hline 2 & 36 & 19 & 353 & 36 & 18 & 354 \\
\hline 3 & 18 & 19 & 371 & 18 & 4 & 386 \\
\hline 4 & 21 & 2 & 385 & 21 & 8 & 379 \\
\hline 5 & 16 & 4 & 388 & 16 & 12 & 380 \\
\hline 6 & 104 & 5 & 299 & 104 & 104 & 200 \\
\hline 7 & 23 & 23 & 362 & 23 & 40 & 345 \\
\hline 8 & 213 & 6 & 189 & 213 & 94 & 101 \\
\hline 9 & 4 & 21 & 383 & 4 & 37 & 367 \\
\hline 10 & 192 & 21 & 195 & 192 & 58 & 158 \\
\hline
\end{tabular}


transforming zeros into missing values has to be carefully monitored but it should be noted that zeros account for $6 \%$ or less of the observations in 15 time series. In a further 2 cases they account for between 5 and $10 \%$. In only 3 series (Calanus in boxes 6,8 and 10) do zeros account for more than $10 \%$ of the observations. In these latter 3 cases all inferences based upon our approach must be treated with caution.

\section{ANALYSIS AND RESULTS}

\section{Deriving the long-term trend and the mean annual cycle}

Reliable seasonal and trend estimates may be derived only if missing and zero values are randomly distributed throughout the year. For the copepods there is significant seasonality in the distribution of zeroes and missing values in boxes 2,3 and 10 (G-test, $p<0.05$ ). In the case of Calanus there is seasonality in the distribution of zeroes and missing values only in region 2 . To minimise the bias introduced by this seasonality we adopted an iterative method to estimate the trend and seasonality. Trend was first estimated using a 12 mo moving average smoother. This trend was subtracted from the log counts, and the average value of the residuals for each month calculated. Ideally, these should sum to zero but, because of seasonality in the distribution of zeroes and missing values and imperfect detrending, this was not always the case. To combat this, we calculated the difference between the 12-monthly sum and zero. This was divided by 12 to yield a 'mean monthly error' which was subtracted from each monthly factor and added back onto the trend values. This provided a first estimate of the seasonal component in each time series. The original time series was deseasonalised by subtracting this first estimate of the seasonality from the it. After this first step we estimated trend by applying a LOWESS (Chambers et al. 1983) filter to the deseasonalised data. The filter window was $15 \%$ of the data which corresponds to approximately 6 yr where there are no missing values. Seasonal components were recomputed by subtracting the LOWESS trend estimates from the original logtransformed counts and calculating monthly averages, again with the zero sum constraint. The final 2 steps in this process (LOWESS smoothing \& monthly averaging) were repeated iteratively until the monthly factor estimates converged. Convergence was usually achieved in 2 or 3 passes. The filter window in the trend estimator is too long to enable us to detect any oscillations of period less than $6 \mathrm{yr}$; however, if these exist they should manifest themselves in the autocorrelation structure of the detrended, deseasonalised data.
To calculate the confidence intervals for each monthly mean it is necessary to take account of the year to year autocorrelation (Diggle 1990). This is done by inflating the standard error of the mean by a factor which, in theory, involves a weighted sum of the values of the autocorrelation function at all lags which are multiples of 12 . These, of course, are based on relatively small subsets of the data, viz, 33 for the first, 32 for the second, etc and are highly variable. We employed a more robust estimator of this factor. It is obtained by smoothing the estimated autocorrelations using a weight function proportional to the first half of a cosine wave of period 20 (yr)

Regional variation of the seasonal cycle was investigated in terms of both magnitude and shape. Regions which share common dynamical characteristics were identified by means of cluster analysis techniques. These were applied to (1) the long-term averagge (log) densities for each box; (2) the mean monthly deviations from these long-term mean densities; and (3) the mean monthly deviations standardised to a $[0,1]$ scale for each box.

We are also interested in determining just how well the 'mean annual cycle' characterises the raw data. To answer this question we have adopted 2 schemes: visual comparison of the mean annual cycle with the cycles for individual years, and comparison of the variances in the raw data, the detrended data and the detrended, deseasonalised data.

\section{Copepods}

Fig. 2 illustrates the log-transformed copepod counts together with the estimated long-term trends. Much of the variability about the long-term trends in these figures is attributable to the seasonal variation. This is discussed in a later section. The data for boxes 6,8 and 10 are too sparse for reliable trends to be determined. It is immediately apparent that the data are comparatively sparse for boxes 1 (Northern North Sea) and 6 (northern British coastal strip) and especially sparse in boxes 8 (southern continental coastal strip) and 10 (Danish coastal strip) In particular there are no data for box 8 in the late 1960 s and almost no data for box 10 during the 1970 s

For easier comparison of their details we replot the trend curves for copepods in boxes 1 to 5,7 and 9 (the data for the remaining boxes are too sparse for reliable trends to be determined) in Fig. 3. The copepod concentrations are 2 to 3 times greater in the central latitudes (regions 6, 4 and 10) and in region 8 than elsewhere. The mean population abundance has remained remarkably stable throughout the sampling period: in any region the maximum mean density is only approx- 

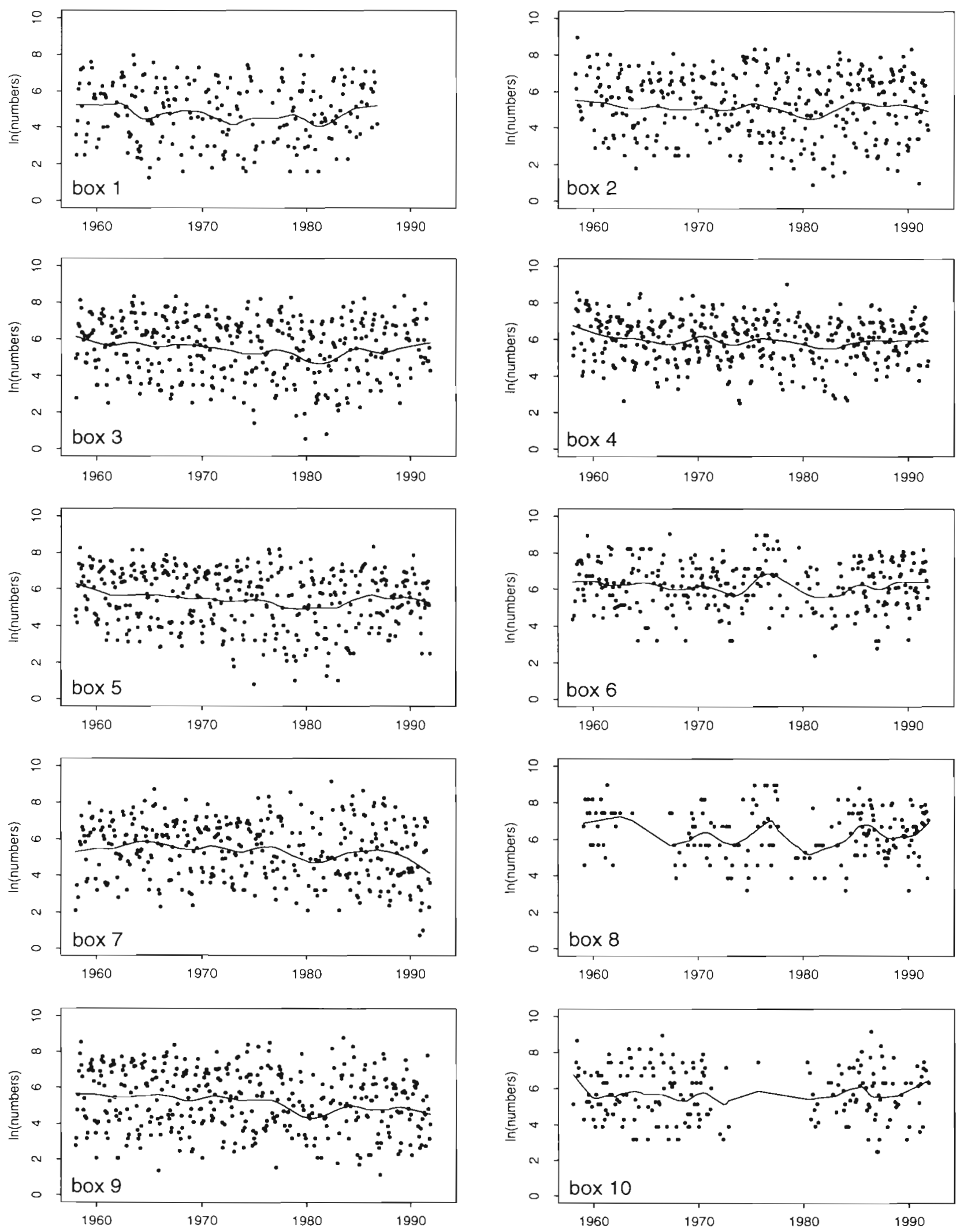

Fig. 2. Natural logarithms of mean small copepod counts $\left(\mathrm{m}^{-3}\right)$ for each month in each region of the North Sea together with the estimated trend 


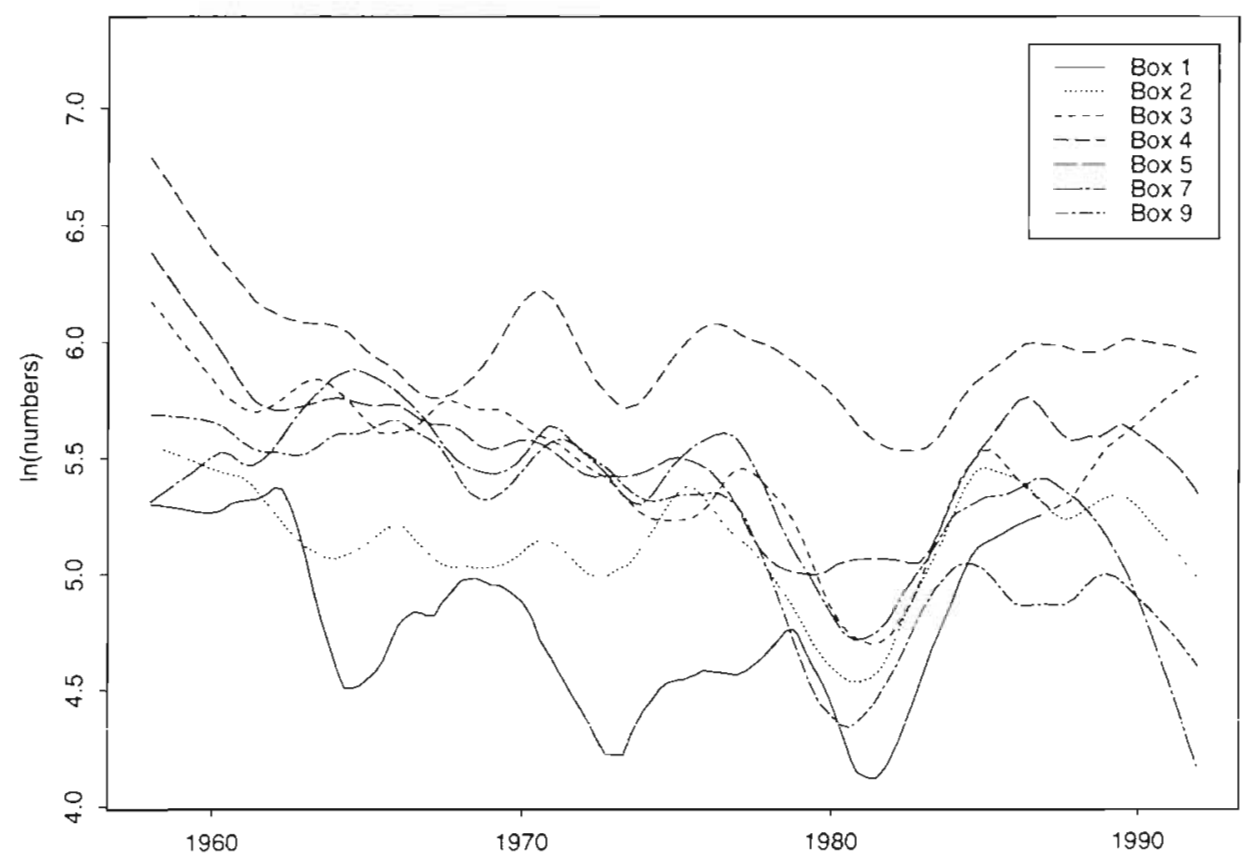

Fig. 3. Small copepod trends in boxes 1 to 5,7 and 9 imately 10 times the minimum mean density. In the northern and central boxes of the North Sea it seems that there was a gradual decline in copepod numbers from the early to mid 1960s until the mid 1970s. In some regions there is evidence of a small rise in numbers during the later 1970s; however, this was followed by a dramatic decline around 1980 in all northern and central regions. Further south there is less evidence of any decline during the 1960 s and 1970 s but in most of these boxes there is a clear depression of numbers around 1980. Since then, most regions seem to have made a consistent recovery, but in regions 7 and 9 the recovery was short lived. The intrinsic autocorrelation in the individual trends renders strict significance tests of the degree of covariation between the trends in different areas extremely unreliable, but inspection of Fig. 3 indicates that all the areas show some covariation. The covariation is particularly strong between boxes 3, 5, 9 and 7 . Box 4 also shows a similar pattern. The dynamic of box 1 appears to lead that of box 4 in the first half of the time series and lag that of box 4 in the second half.

Fig. 4 presents the (detrended) data for copepods in box 3 for each year (1958 to 1992) superimposed upon the mean annual cycle. The close correspondence between the mean cycle and the individual years' data is reflected in the tight confidence bounds associated with the monthly means (Fig. 5): it seems that we know the mean seasonal cycle very well despite the considerable interannual variability in month by month abundance. In the case of 'small copepods' the areas with the highest mean densities (boxes $4,6,8$ and 10) also form a group which exhibits smaller seasonal amplitudes. In these areas, summer densities are only about 10 times greater than winter densities. Elsewhere the ratio is nearer 30 -fold. Detrending and deseasonalising the copepod data explains between $46 \%$ (box 6) and $72 \%$ (box 2) of the total variance (mean $64 \%$ ), detrending alone explains an average of just $5 \%$ of the total variance. There is no apparent spatial pattern in the percentage of variance explained.

The various boxes exhibit a continuum of seasonal profiles. Box 8 represents one end of this continuum: its winter minimum occurs in March (rather than January or February as elsewhere) and is exceptionally sharp. Following the summer maximum in June, numbers decline comparatively rapidly. The cycle is somewhat irregular in boxes 6,7 and 10 (though this may be an artefact of the comparatively sparse data) but they all appear to show a gradual decline of numbers through the summer and a well-defined minimum in February. In boxes 3, 4 and 5 the cycle is regular and changes of slope are gradual. In boxes 1,2 and 9 the cycle is regular but there are abrupt changes of slope: numbers rise very rapidly in spring, remain approximately constant throughout the summer, and then decline very rapidly.

\section{Calanus}

Fig. 6 illustrates the log-transformed data together with the smoothed trend for Calanus in the North Sea. Densities are highest in the northern and central North 

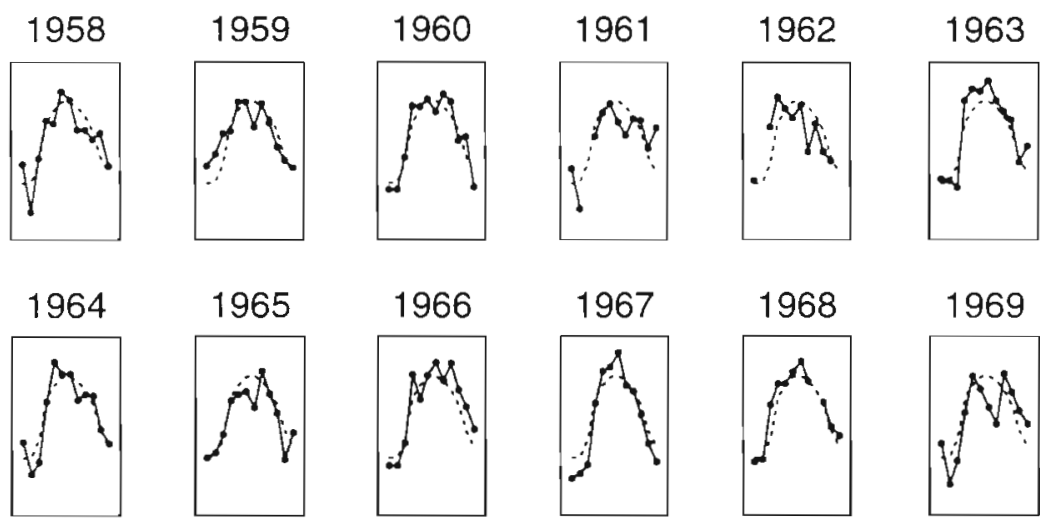

1968

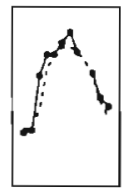

1969
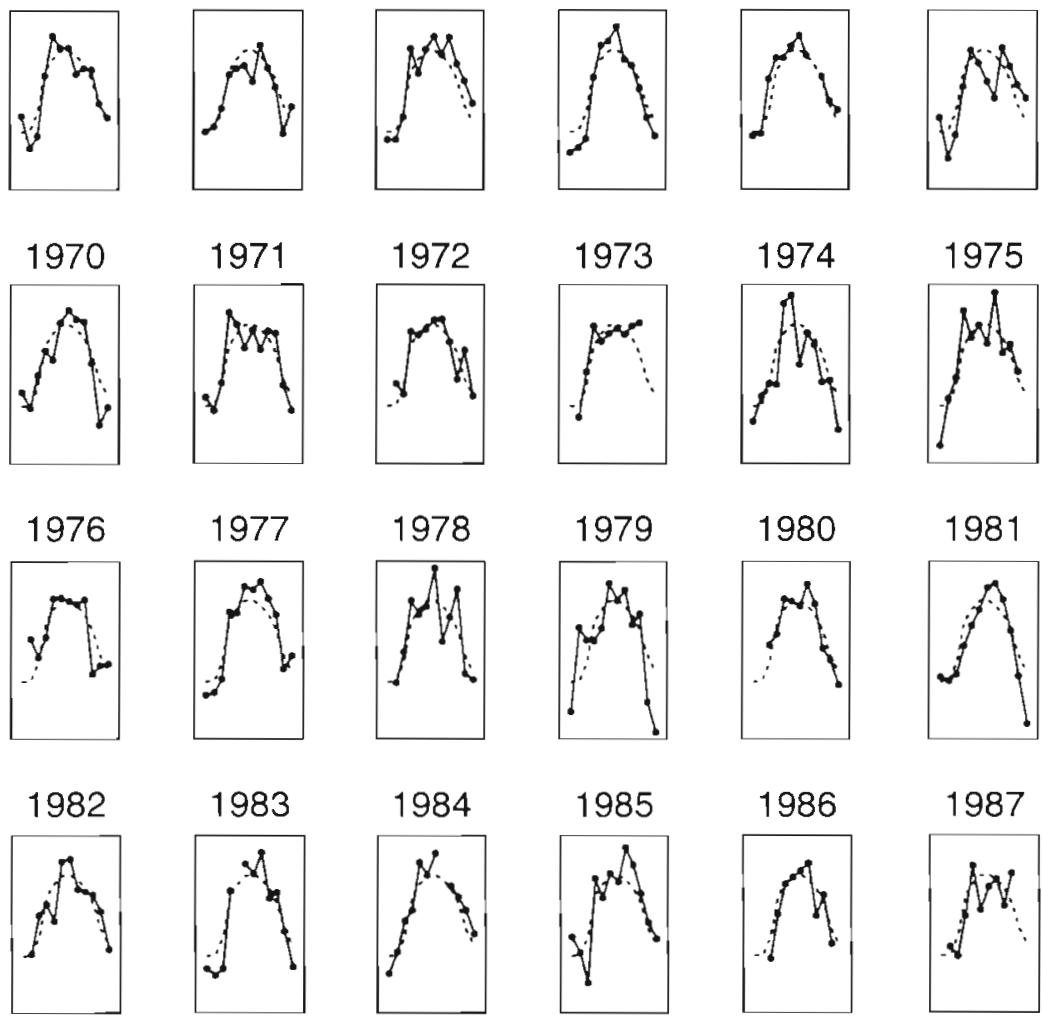

1981
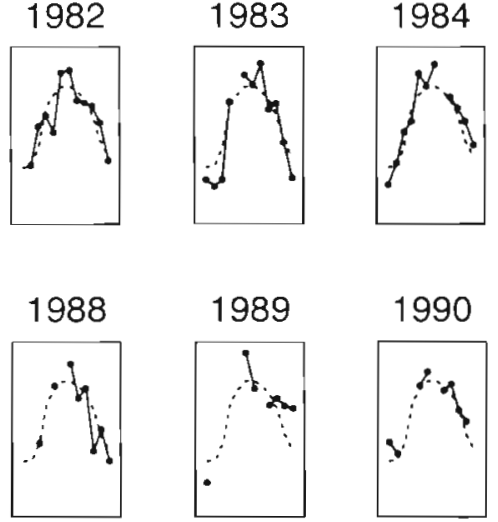
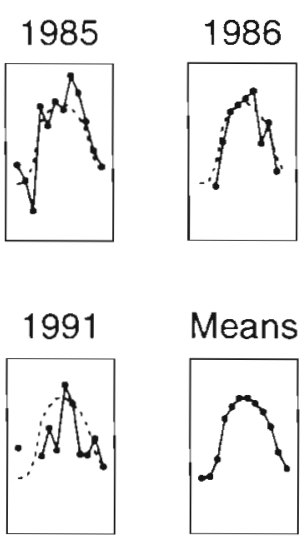

Means

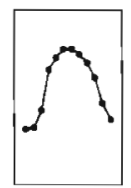

exhibited up to 20 -fold variations, these being greatest in the more northerly regions. Calanus in box 2 shows a particularly marked decline during the 1960s and the high densities of the late 1950s appear to have been exceptional since they have not been regained. The decline during the 1960s and early $1970 \mathrm{~s}$ is reflected (to a lesser extent) in boxes 1,4 and 9 , but absent in boxes $3,5,6$ and 7 . There is less between-box covariation of the Calanus time series than was the case for the copepod time series, but boxes 1,2 and 4 and boxes 5,7 and 9 appear to form 2 covariation groups (Fig. 7).

In Fig. 8 we present the detrended, monthly data with the monthly means and their $95 \%$ confidence intervals superimposed on top. As with total copepods, the scatter of points about the monthly means spans several orders of magnitude, but year on year negative autocorrelations ensure that the confidence bounds on our estimates of the mean annual cycle are surprisingly tight. For Calanus the process of modelling the data (by detrending and deseasonalising) explains between $13 \%$ (box 4 ) and $55 \%$ (box 2) of the variance (mean $35 \%$ ). Detrending alone accounts for an average of $11 \%$ of the total variance ( 16 to $20 \%$ in boxes $2,8,9$ and $10 ; 5$ to $8 \%$ in the remaining boxes). With the exception of box 4, this model predicts Calanus dynamics better in the deep water regions of the North Sea than in the shallow, southern coastal regions where Calanus is a sporadic visitor rather than an endemic.

Sea (boxes 1 to 5 ; mean value of the trend $>2$ ). Elsewhere (boxes 6 to 10 ) mean $\log$ numbers are $<1.5$. Interestingly, the mean density in box 5 is rather more similar to that in boxes 1 to 3 than to that in its northerly neighbour, box 4 . This apparent inversion in which box 5 is dynamically more similar to the northern boxes and box 4 similar to the southern boxes is also repeated in other features of the dynamics (shape and amplitude of the seasonal cycle). Over the $34 \mathrm{yr}$ which the data span, mean regional densities have
The 10 regional boxes can be grouped into 4 dynamical classes on the basis of their seasonal cycles of Calanus abundance. In class 1 (boxes 1 and 2) the spring increase does not begin until March, but is extremely rapid thereafter. Their numbers increase nearly 30 -fold in only 2 mo. In box 1 , numbers remain approximately constant until October after which they decline rapidly. In box 2 , they appear to fall during mid summer before rising to a second, higher maximum in September 


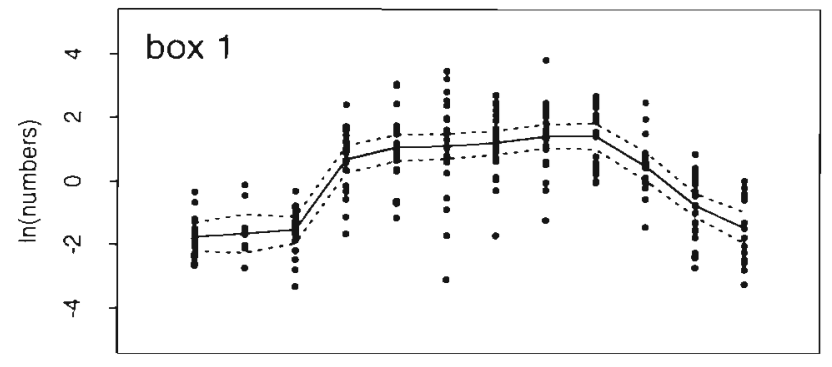

Jan Feb Mar Apr May Jun Jul Aug Sep Oct Nov Dec

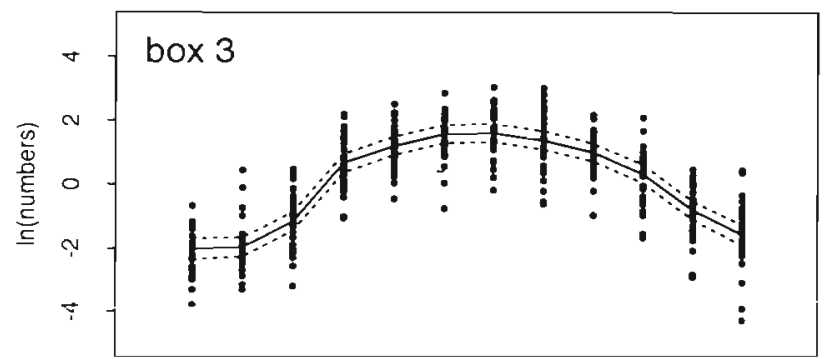

Jan Feb Mar Apr May Jun Jul Aug Sep Oct Nov Dec

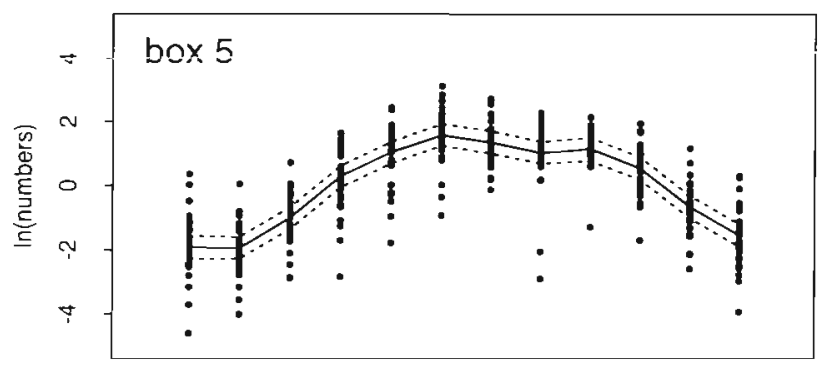

Jan Feb Mar Apr May Jun Jul Aug Sep Oct Nov Dec

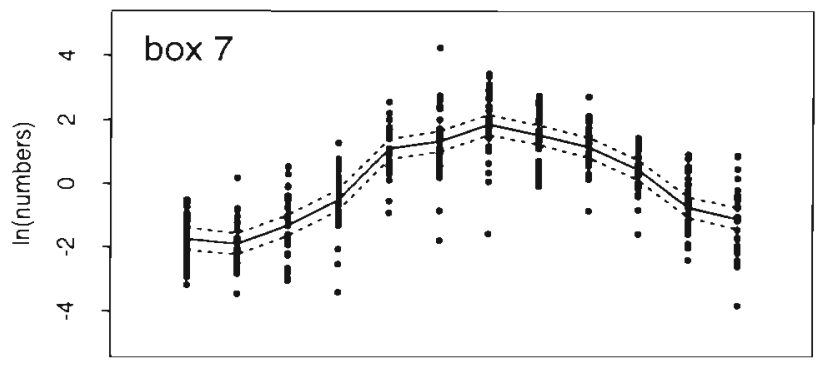

Jan Feb Mar Apr May Jun Jul Aug Sep Oct Nov Dec

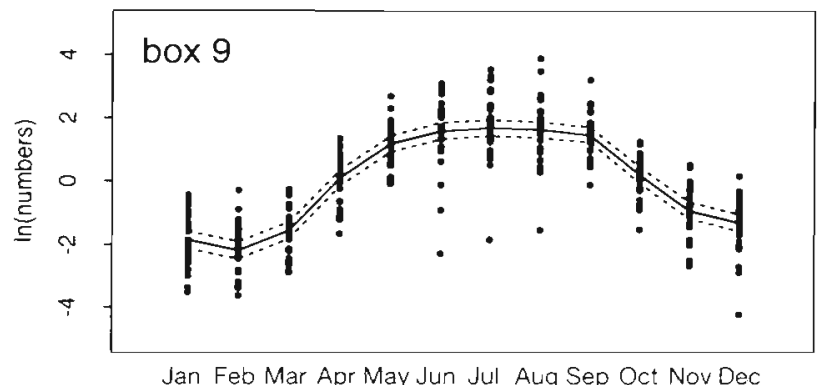

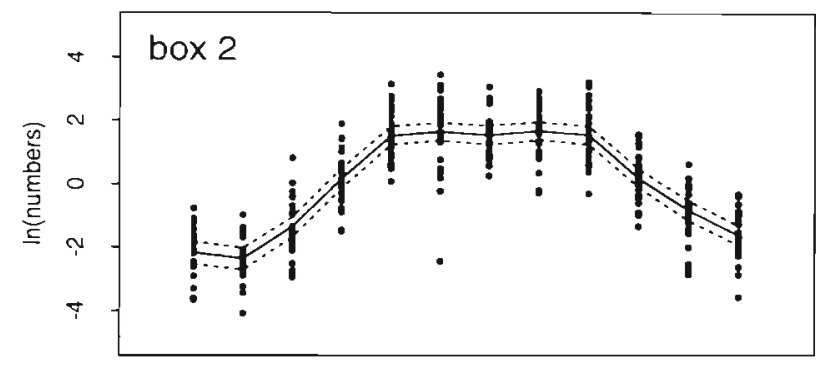

Jan Feb Mar Apr May Jun Jul Aug Sep Oct Nov Dec

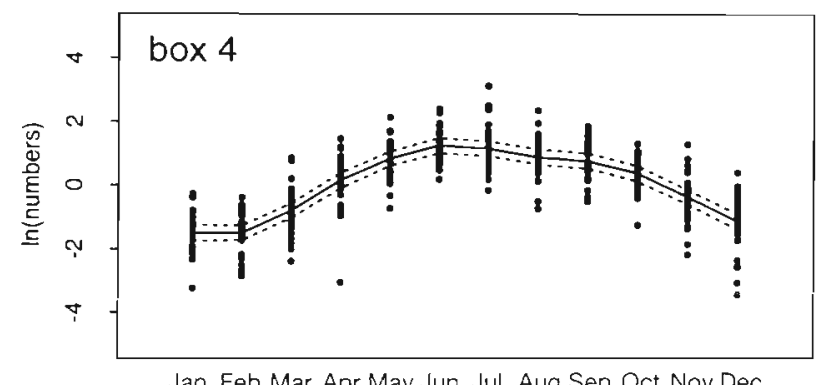

Jan Feb Mar Apr May Jun Jul Aug Sep Oct Nov Dec

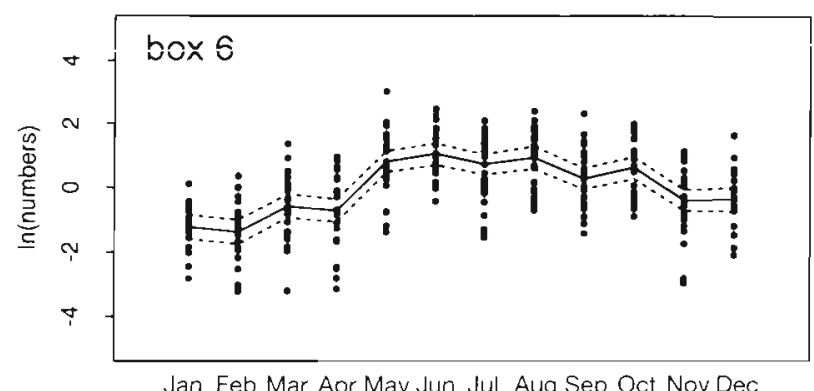

Jan Feb Mar Apr May Jun Jul Aug Sep Oct Nov Dec

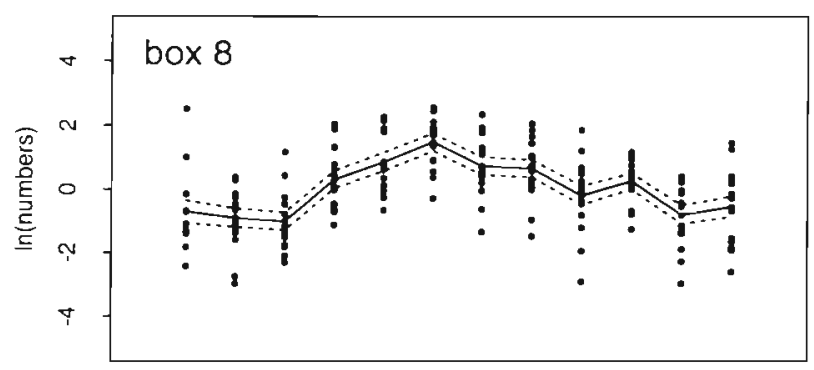

Jan Feb Mar Apr May Jun Jul Aug Sep Oct Nov Dec

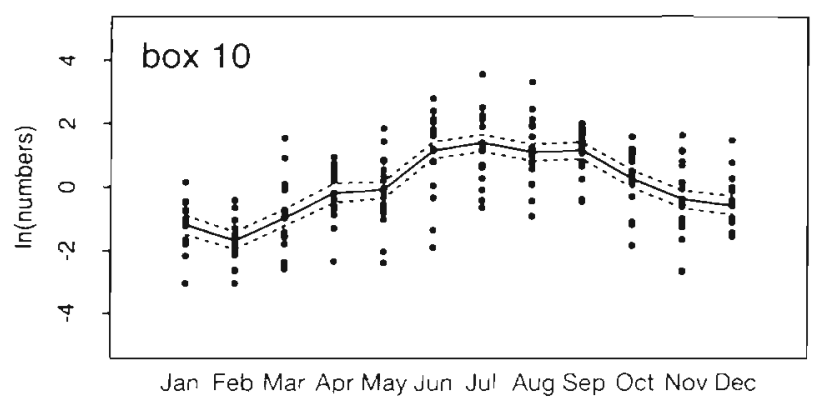

Fig. 5. Mean monthly deviations from the instantaneous value of the estimated trend curve for copepods together with both the $9.5 \%$ confidence bounds on the means and the detrended data 

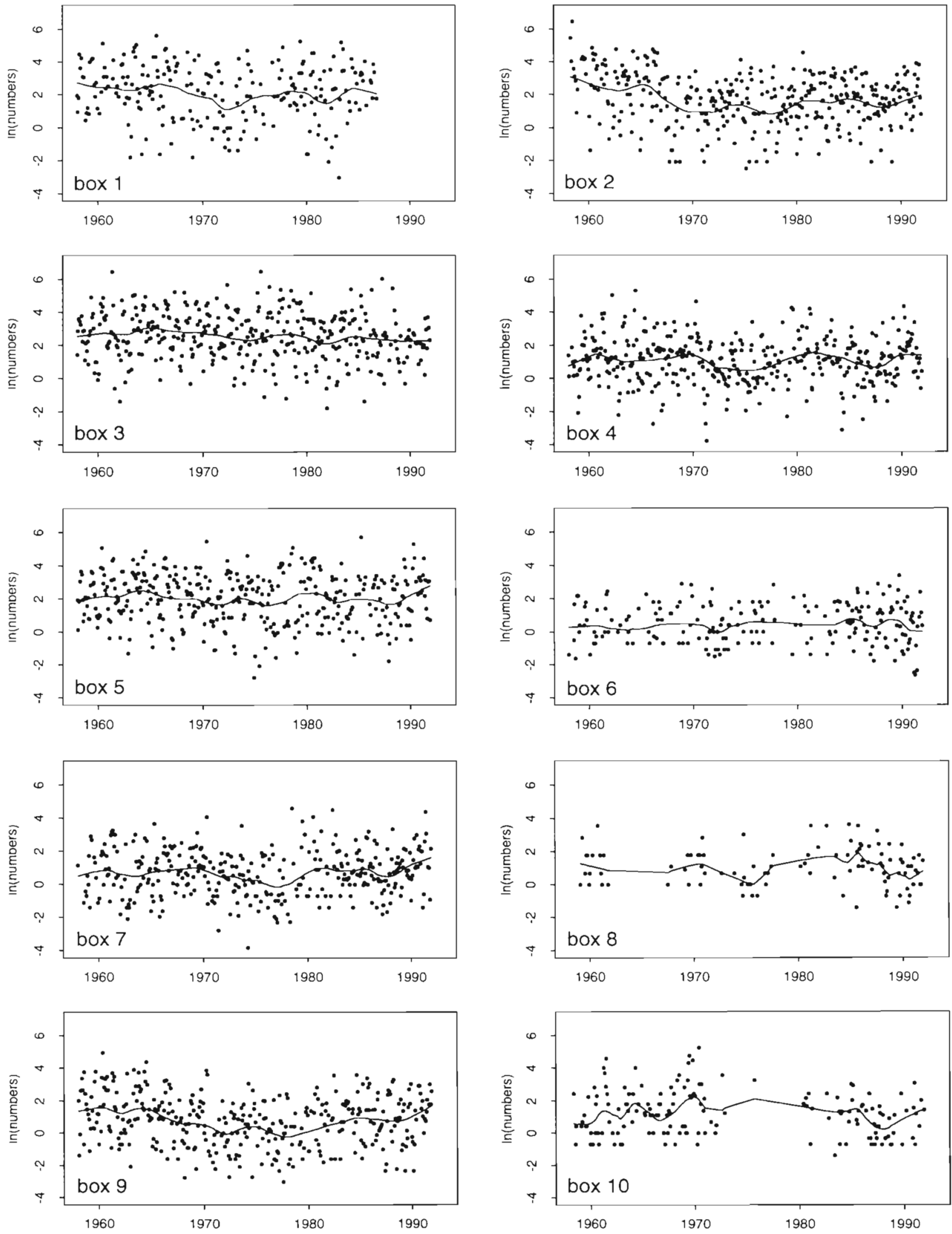

Fig. 6. Natural logarithms of mean Calanus counts $\left(\mathrm{m}^{-3}\right)$ for each month in each region of the North Sea together with the estimated trend 


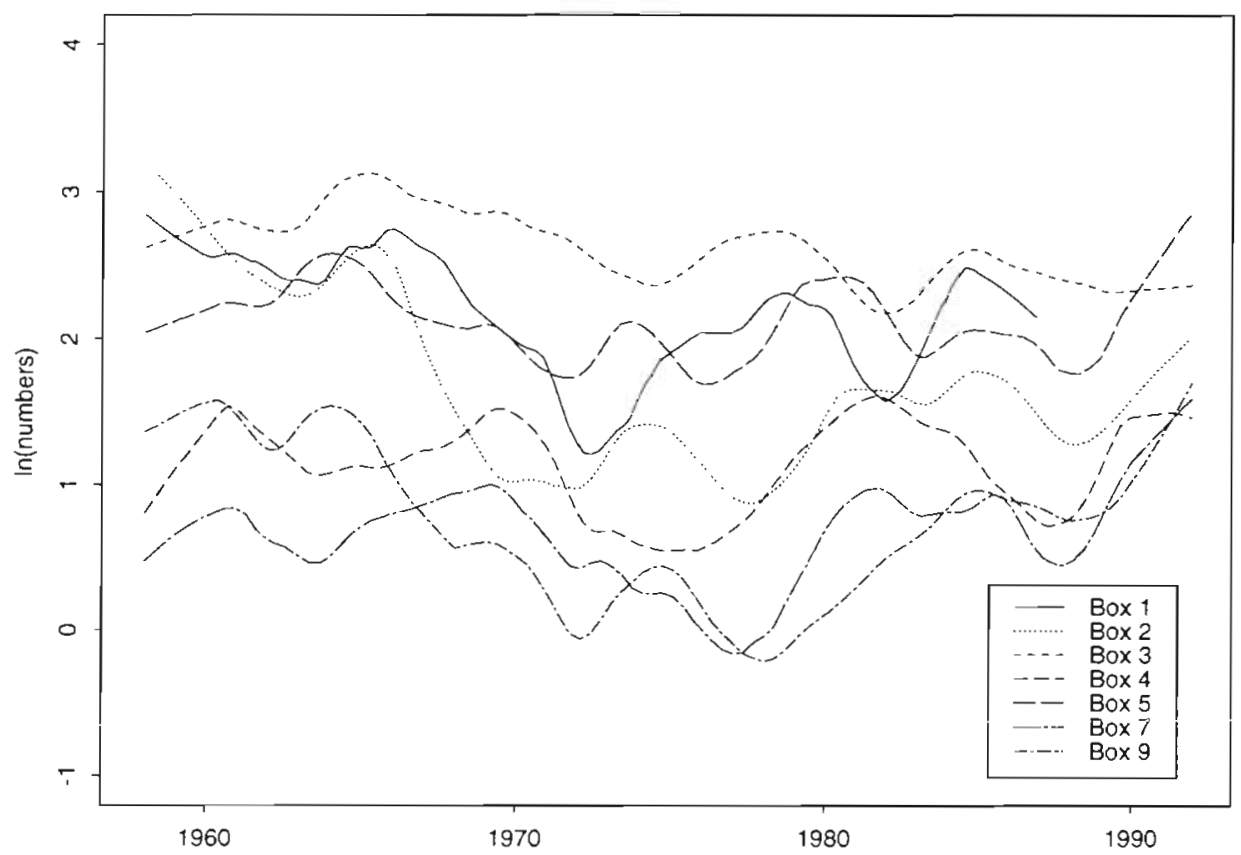

Fig. 7. Calanus (copepodite stages 5 and 6 ) trends in boxes 1 to 5,7 and 9
In class 2 (boxes 3 and 5) the amplitude of the annual cycle is similar to that in boxes 1 and 2, but the profile is very different. The spring increase starts in January or February, and is more gradual. After the peak in May, numbers decline steadily throughout the rest of the year rather than remaining high.

In the remainder of the North Sea data for Calanus are more sparse which makes it difficult to determine the seasonal cycle reliably. All the remaining boxes share a common feature: maximum mean numbers in the year are only about 10 times greater than the minimum. In class 3 (boxes 4, 7 and 10) Calanus numbers are higher during the summer than during the winter, but very variable month to month. The final dynamical class corresponds to boxes 6,8 and 9 . In these boxes Calanus is most abundant during the period August to December and comparatively rare throughout the rest of the year. Comparison with Fig. 12 of Colebrook (1985a) suggests that the Calanus population of these latter 3 areas is dominated by $C$. helgolandicus while C. finmarchicus dominates elsewhere.

\section{Residuals}

\section{Autocorrelation}

After the trend and seasonality have been removed from the data the residuals exhibit approximately a 40 fold variation regardless of season. They also retain some correlation structure. For both the copepods (Fig. 9) and Calanus (Fig. 10) there is a tendency for a significant positive correlation at lag 1 (mo). Similarly, though not usually, significant at the $5 \%$ level, both groups have a tendency to exhibit a cluster of negative correlations around lag 7 . The positive correlation at lag 1 probably reflects the fact that samples taken in successive months are not entirely independent in the sense that many of the individuals comprising the population sampled in the first month will still be alive and contributing to the population which is sampled in the second month. The negative correlations exhibited around lag 7 suggest that though season is the major determinant of numbers, there is an additional historical influence. Many series also exhibit a cluster of positive correlations around 36 to 40 mo lag. Several other authors have found evidence of significant autocorrelations at lags of 3 to $3.5 \mathrm{yr}$ (e.g. Colebrook 1981, Colebrook \& Taylor 1984) which they attribute to a corresponding cycle in the frequency of westerly winds. It is suggested that wind fields influence plankton dynamics through processes such as wind-driven advection of plankton communities or the influence of wind upon water column stability.

\section{Cross-correlation}

Finally, we looked for cross-correlations in the residuals remaining after each time series had been detrended and deseasonalised. In order to avoid the confounding effects of the internal correlation structure in each series, the (short term) correlation structure was first removed to yield a 'prewhitened' series. 


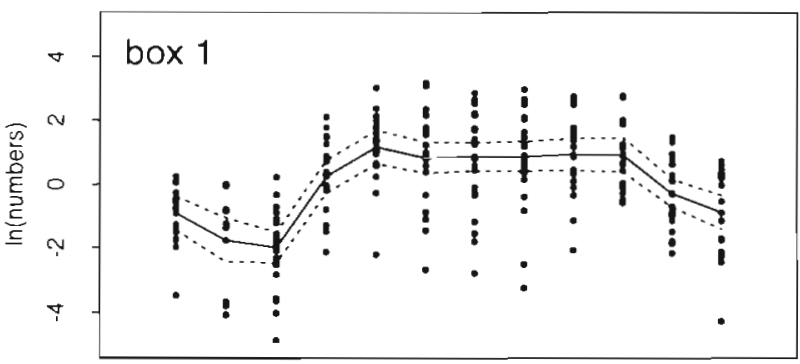

Jan Feb Mar Apr May Jun Jul Aug Sep Oct Nov Dec

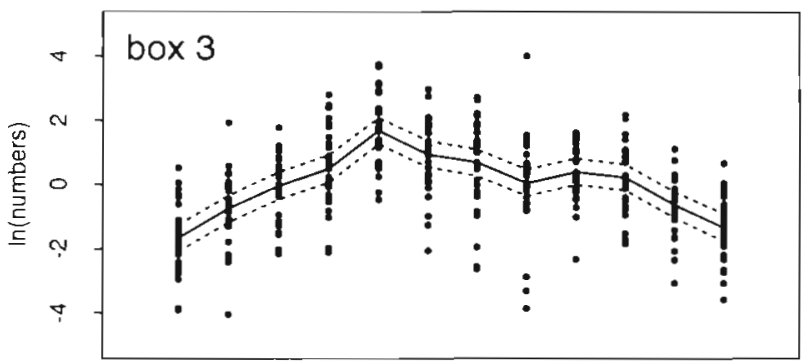

Jan Feb Mar Apr May Jun Jul Aug Sep Oct Nov Dec

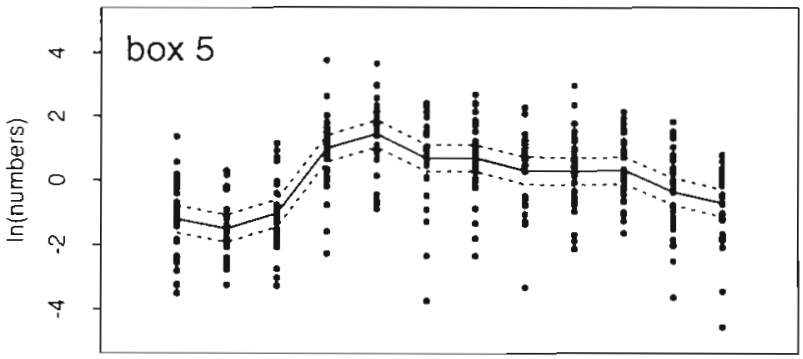

Jan Feb Mar Apr May Jun Jul Aug Sep Oct Nov Dec

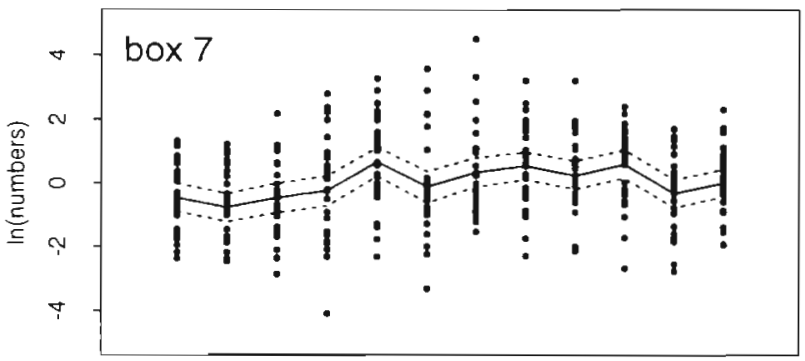

Jan Feb Mar Apr May Jun Jul Aug Sep Oct Nov Dec

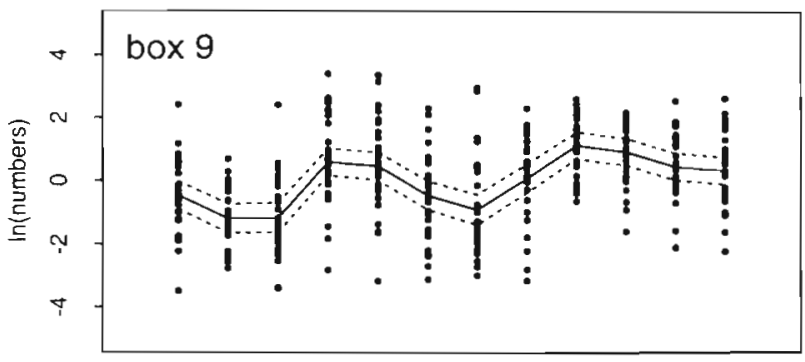

Jan Feb Mar Apr May Jun Jul Aug Sep Oct Nov Dec

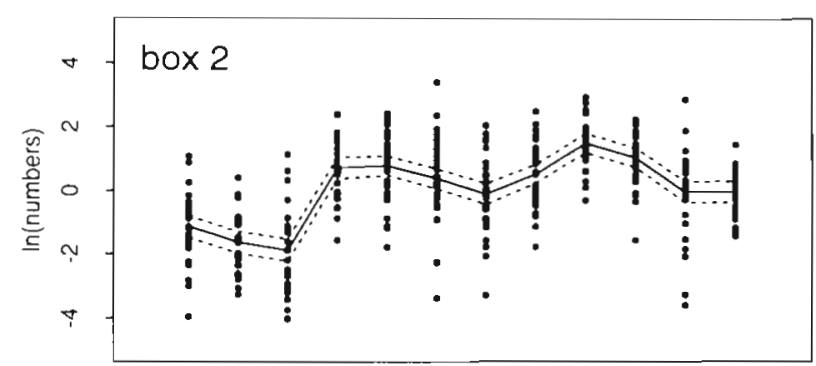

Jan Feb Mar Apr May Jun Jul Aug Sep Oct Nov Dec

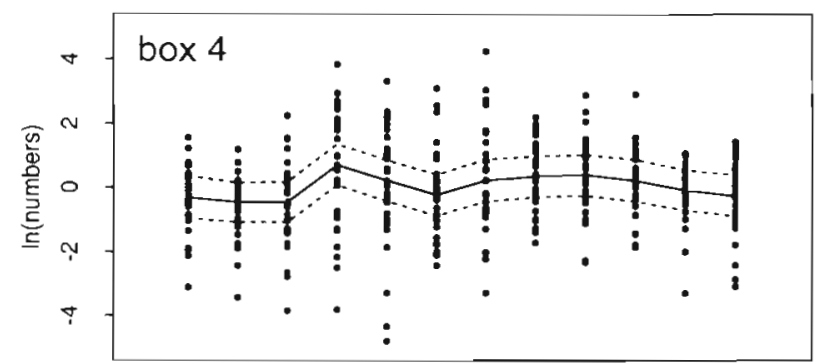

Jan Feb Mar Apr May Jun Jul Aug Sep Oct Nov Dec

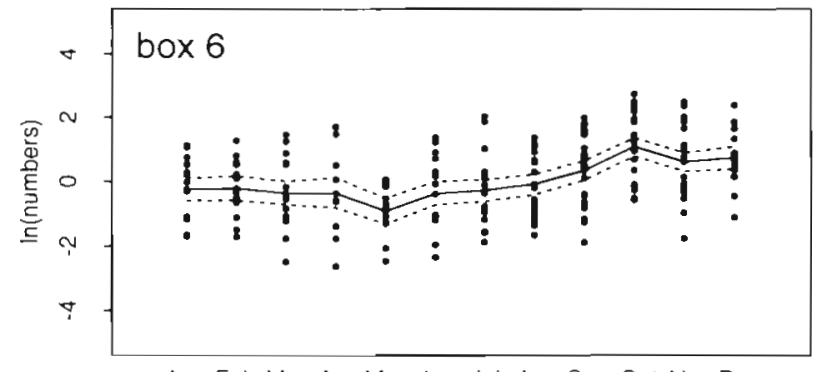

Jan Feb Mar Apr May Jun Jul Aug Sep Oct Nov Dec

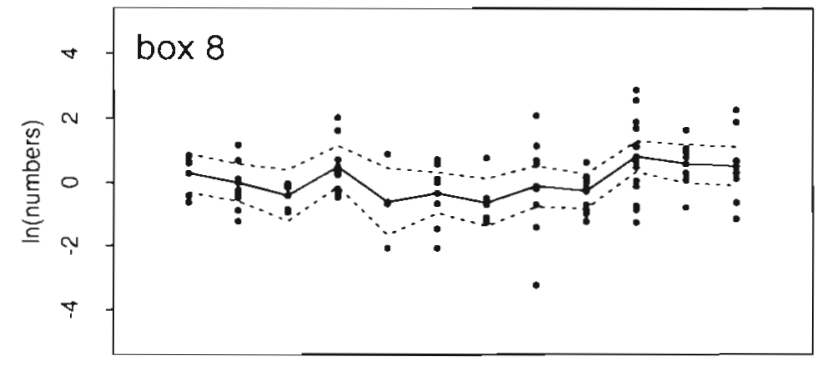

Jan Feb Mar Apr May Jun Jul Aug Sep Oct Nov Dec

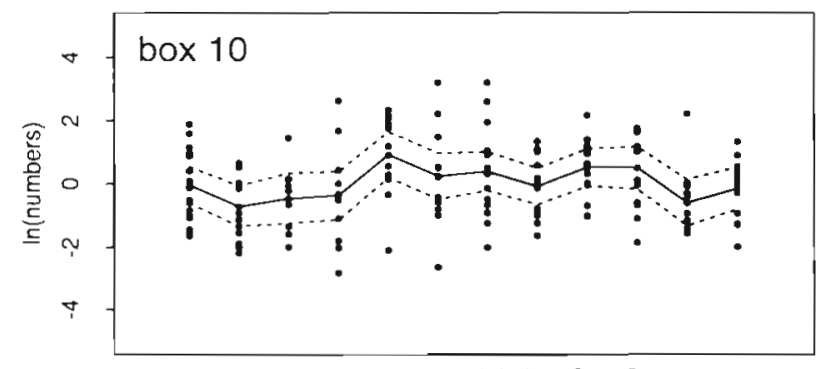

Jan Feb Mar Apr May Jun Jul Aug Sep Oct Nov Dec

Fig. 8. Mean monthly deviations from the instantaneous value of the estimated Calanus trend curve together with both the $95 \%$ confidence bounds on the means and the detrended data 

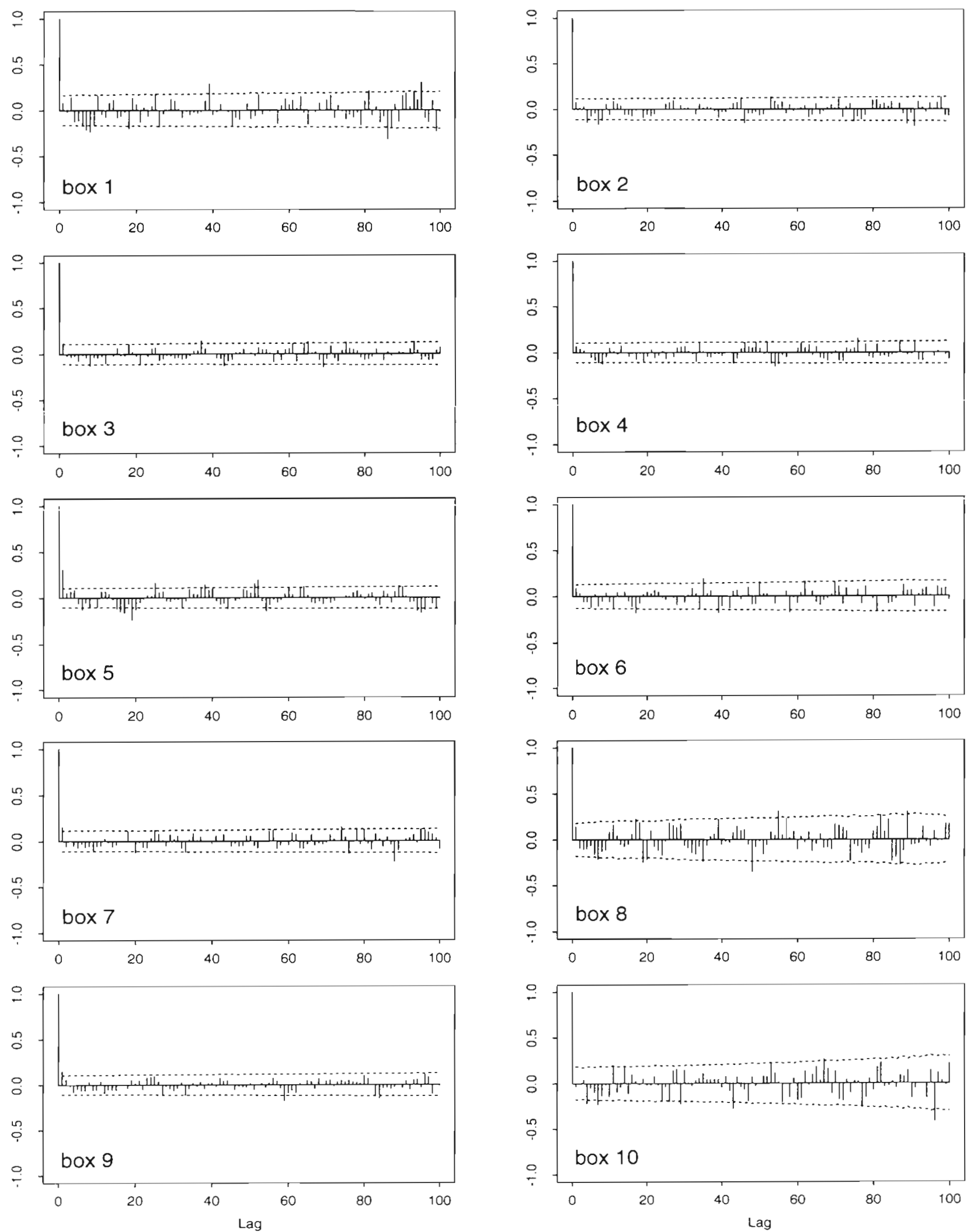

Fig. 9. Autocorrelation functions for the residuals which remain after detrending and deseasonalising the copepod data. Dashed lines represent $5 \%$ significance level for white noise 

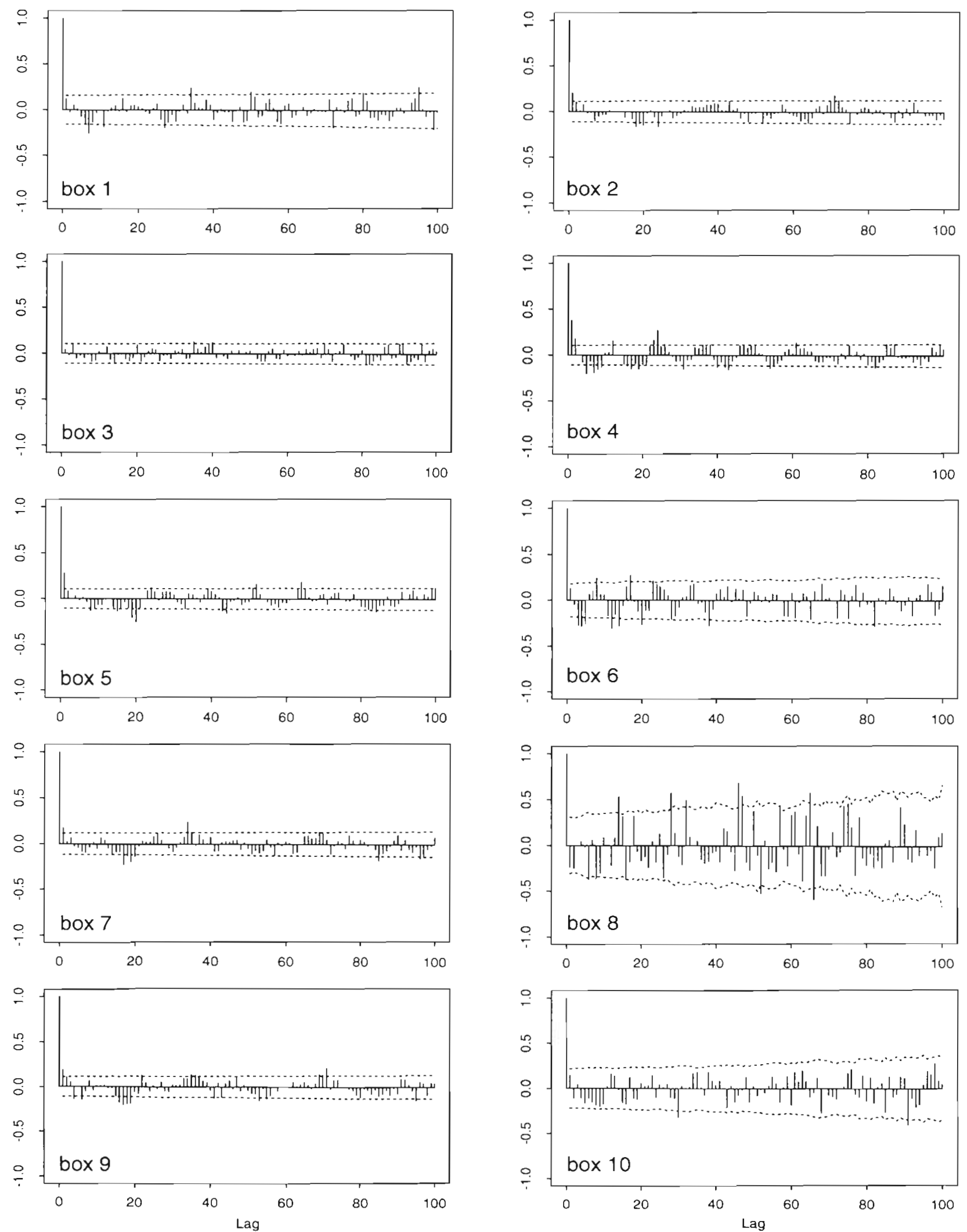

Fig. 10. Autocorrelation functions for the residuals which remain after detrending, and deseasonalising the Calanus data. Dashed lines represent $5 \%$ significance level for white noise 
In most cases the correlation structure could be removed by using an ARMA model. In general, these were autoregressive models of orders varying from 1 to 10. In some cases it was also necessary to introduce a moving average term of order 12 .

In the case of the copepods there are no significant correlations between the U.K. coastal boxes (boxes 6 and 7 ) and any of their neighbours. Elsewhere there is almost always a significant positive cross correlation at lag 0 and often a significant positive correlation at lag 1. In some cases there are also correlations at lags of up to 6 months but we are inclined to regard these as being spurious. In all cases the correlation coefficient, though significant, is comparatively small (0.2 to 0.4$)$. Boxes 5 and 9 stand out as being 'driven' by their neighbours in the sense that they show significant positive cross correlations with their neighbours with a lag of 1 mo. This might indicate that current-driven advection of plankton from neighbouring areas has a significant influence upon the dynamics of these 2 areas. Elsewhere, however, significant cross-correlations are in the 'wrong' direction to be the result of currentdriven advection (e.g. box 3 leads box 10; box 2 leads box 1). For Calanus, boxes 1 and 3 are strongly (positively) correlated at $\operatorname{lag} 0$, and there is also a significant negative cross-correlation (box 1 leads box 3 ) at lag 4 mo. Boxes 2 and 3 are also positively correlated at lag 0 , and there is a second significant positive correlation (2 lags 3) at 4 mo. Boxes 1 and 2 are not significantly correlated at lag 0 , but there are highly significant negative correlations at lags 6 and 7 (box 2 leads). Elsewhere in the North Sea the regional Calanus dynamics are uncorrelated with one another.

In the case of Calanus significant positive correlations at lag 0 are frequent, and correlations at lag 1 are found between many of the boxes of the southern North Sea. There are fewer significant long-term lags, and as with copepods we are inclined to ignore these.

\section{DISCUSSION}

\section{Trend}

The major feature of the time series for 'small copepods' is the apparent decline and subsequent recovery of their numbers. This has been reported by several authors (Colebrook 1985b, Aebischer et al. 1990). Aebischer et al. (1990) suggest that decline is a consequence of changes in the frequency of westerly weather whilst Dickson et al. (1988) suggest that the change was a result of changes in the frequency of northerly winds. Taylor. et al. (1992) demonstrated significant correlations between copepod numbers in the northern North Sea and the position of the north wall of the Gulf stream, but found the correlations to be non-significant in the southern North Sea. He suggests that the correlation is mediated through an influence on atmospheric circulation. Their observation that correlations are significant only in the northern North Sea probably reflects the fact that Atlantic frontal systems (which are greatly influenced by the Gulf Stream) tend to pass over the northern, rather than the southern North Sea. Though it is difficult to envisage a mechanism, it is possible that the fact that the southern North Sea does not stratify during the summer further decouples it from the Gulf Stream influence.

In view of this compelling evidence for a relationship between wind fields and copepod numbers it is surprising to that we find there to be so much regional variation in the extent, duration, and timing of the copepod decline. Still more surprising is the observation that though the water circulation patterns in regions 4 and 5 are primarily wind driven (in contrast to patterns elsewhere in the North Sea), these regions show the smallest variations in average copepod abundance

The Calanus trends differ from those of the small copepod class. Not only do the corresponding small copepod and Calanus trends differ within a box, but in addition, boxes which covary in terms of their small copepod trends often fail to do so in terms of their Calanus trend. The difference between the small copepod and Calanus trends are greatest in the southern North Sea. This is natural since juvenile Calanus will constitute approximately $50 \%$ of the 'copepod' class in northerly waters, but very much less in southerly waters of the North Sea. Unfortunately, we are unable to suggest what processes are determining the changes in the average abundance of Calanus.

The only other published long-term time-series of zooplankton abundance in the North Sea of which we are aware is one dating back to 1969 for the Northumberland coast (Roff et al. 1988, Evans \& Edwards 1993). This spans much of the period covered by the CPR data but sampling was by means of $50 \mathrm{~m}$ long vertical hauls. Evans \& Edwards (1993) also found Calanus to be rare during the mid 1970 s and a depression in numbers of most smaller copepod species around 1980 . Thus, their data exhibit similar trends to those found in the CPR data taken as a whole. Surprisingly, however, the CPR data for region 6 (which includes the Northumberland coast) do not indicate any decline of Calanus in the 1970s, and indicate that copepod decline was a rather more long-lived phenomenon that the data of Evans \& Edwards (1993) suggest. This might be explained either by the comparative sparsity of CPR data for box 6 or the observation that much of the CPR data for box 6 stems from Scottish waters. 
Long-term average copepod abundances are highest in the central latitudes of the North Sea (boxes 6,4 and 10) and in box 8 . Inspection of the data indicates that this is because minimum (non-zero) levels recorded in these regions are higher than elsewhere, rather than because the maximum levels are very much greater Possibly, the high nutrient inputs into box 8 by the Rhine River might allow elevated primary production rates which in turn support elevated zooplankton populations, at least some of which would be swept into box 10. Nutrient import via river run-off and from the Atlantic might offer a similar explanation for the elevated levels in box 6 , some of which would be washed into box 4 (and box 7 which places next in a ranking of boxes by copepod abundance).

It is also possible that because we have excluded zeros from our data, we have biased our estimate of long-term means upwards. This would be most marked in those boxes for which zeros are most common. Comparison of the long-term means with the frequency of zeros (Table 1) indicates that this is unlikely

One might also ask whether it is significant that though the minimum numbers ever attained differ between region, the maximum numbers are very similar. Whilst it is tempting to search for a biological mechanism to explain this pattern, we believe that there are more likely explanations based upon the CPR sampling device and the recording protocol. The most obvious explanation lies in the manner in which the CPR tows are analysed. The CPR mesh is sampled and counts of the abundance of each taxa are made; however, it is not these raw counts which are recorded. Rather, each count is assigned to a particular frequency class. For example, a count of between 12 and 25 individuals will be scored as frequency class 5 (Colebrook 1975). Empirically, the mean number of individuals in samples falling into this frequency class has been found to be 17 (Rae 1952) and this value is used in converting from the CPR frequency records back to estimates of numerical abundance. Since the width of the frequency classes increases exponentially, the resolution of the CPR records is poorest when individuals are most abundant. The exponential recording system tends to introduce an artificial ceiling to the estimated abundance which may not be present in reality. Aside from this bias arising from the protocol, it is possible that the CPR device becomes saturated at high zooplankton abundances and consequently its sampling efficiency declines.

\section{Seasonality}

The seasonal cycles of both the 'small copepod' class and of Calanus show broadly similar latitudinal trends.
In particular the spring increase and autumn declines are very much more rapid in the northern areas of the North Sea than in the southern areas. In northern regions the rapid spring rise in both copepod and Calanus numbers is at the limits of credibility if it is to stem from in situ reproduction alone (roughly 20-fold increase in numbers in approximately 1 mo which would require that approximately $13 \%$ of eggs survive to adulthood assuming a generation time of approximately 1 mo and a per-capita fecundity of 150 eggs). Rather, we believe it to be a consequence of the import of large quantities of zooplankton from the North Atlantic shelf region. We have corresponding CPR data for small copepods and Calanus 5 and 6 in the regions immediately outside our boundaries to the North Sea. These data indicate that the numbers of small copepod and Calanus 5 and 6 are higher in the boundary regions of the northern North Sea than they are within the northern North Sea during January and February. Therefore, advection of water from the boundary regions together with its associated plankton will increase the plankton densities within the northern North Sea (even in the absence of any active retention mechanism). Both Fransz \& Diel (1984) and Backhaus et al. (1994) have suggested that the North Sea population of $C$. finmarchicus is not indigenous but maintained by an annual import of copepodite stage $5 \mathrm{~s}$ from the North Atlantic each spring - a suggestion to which our findings lend some support.

Further south, the waters are less influenced by import of Atlantic water and the more gradual rise in zooplankton numbers during spring arises primarily from the hatching of overwintering eggs, and in situ reproduction (Fransz 1975).

Differences in the zooplankton community composition probably also explain the differing pattern of copepod autumn decline in northern and southern waters. In the northern regions of the North Sea the small copepod community is dominated by Paracalanus parvus, Pseudocalanus elongatus and juveniles of Calanus finmarchicus. The majority of $C$. finmarchicus and Pseudocalanus elongatus overwinter in deep water (beyond the reach of the CPR) (Bathmann et al. 1990) and the migration to deep water appears to be determined by day length (Miller et al. 1991) which will lead to a synchronised, rapid decline in population numbers in surface waters. Paracalanus parvus and Pseudocalanus elongatus remain relatively abundant in southern waters but other small copepods such as Acartia clausi and Temora longicornis also become abundant. A. clausi overwinters by means of resting eggs whilst $T$. longicornis remains active throughout the winter. An excess of mortality over recruitment will lead to a gradual attrition of numbers in both species during winter, but there is no reason to expect an 
abrupt decline arising from synchronised mortality or migration.

A latitudinal trend in the balance between Calanus finmarchicus and $C$. helgolandicus probably explains the latitudinal change in the dynamics of the Calanus. In the central and southern North sea $C$. helgolandicus replaces $C$. finmarchicus. Though physically similar, the 2 species exhibit differing life-history strategies in the North Sea: they feed at different depths (Williams 1985) and more importantly, it seems that the C. finmarchicus population is sustained by the immigration of adults from the Atlantic during spring, while there is evidence that $C$. helgolandicus population is self sustaining and even remains reproductively active through the winter (Hay et al. 1991). Thus, by analogy with the copepods, we would expect a rapid decline in C. finmarchicus numbers in summer or autumn but a gradual decline for $C$. helgolandicus numbers. The species difference between northern and southern waters might also help to explain why the long-term trends differ between the northern and southern North Sea. Box 4 straddles the boundary between the parts of the North Sea dominated by C. finmarchicus, and the parts dominated by $C$. helgolandicus. It seems likely that one species will dominate in some years and in others the other will dominate. Since the 2 species have differing physiologies, feeding behaviours etc. the annual dynamic will depend upon which species dominates (Williams 1985) and we suggest that this is why the 'mean annual cycle' explains so little of the variation in the detrended data for this region.

One of our more surprising findings is the continued presence of Calanus copepodite stages 5 and 6 in the surface waters throughout the North Sea until around September. Fransz \& van Arkel (1980) report that C. finmarchicus descended below the thermocline in mid June in the Fladen ground area and Rees (1949) reports Calanus to be almost absent form the North Sea south of Aberdeen during the summer months. Similarly, Green et al. (1993) found that numbers of $C$. helgolandicus in vertical hauls taken in the English channel in 1989 peaked in May/June and declined rapidly thereafter.

On average, detrending and deseasonalising process explains nearly $30 \%$ more of the variance in the copepod numbers than in the Calanus numbers. This almost certainly reflects the higher degree of taxonomic aggregation in the copepod group. The spatial distributions of $C$. finmarchicus and $C$. helgolandicus are such that in most boxes, the 'Calanus' class represents the abundance of one or other species and annual variations in the abundance of the species will be reliably detected in the data. In contrast, the copepod class embraces tens of species (though only 3 or 4 are present in significant numbers). Thus, provided that the species' abundances do not all covary across years, year to year fluctuations in the abundance of any one species will tend to masked by the background 'noise' of other species. Indeed, it is possible that 2 (competitor) species may exhibit an inverse relation to one another such that one is abundant when the other is rare, and vice versa. In this case the annual cycle might be expected to be even more stable than would be the case if each species fluctuated independently of the others.

The long-term fluctuations in mean abundance of both Calanus and copepods are small in comparison with both the amplitude of the seasonal cycle, and the scatter of residual deviations which remain after both trend and seasonality have been removed. This suggests that on a year-to-year basis, the zooplankton community of the North Sea is remarkably stable (at the coarse taxonomic scale we have used in this analysis). In addition, because the residuals which remain after detrending and deseasonalising are substantial, comparison of incoming CPR data with predictions made on the basis of past data and the simple analytic techniques discussed in this paper may not enable the user to detect any but the most abrupt and extreme changes in zooplankton dynamics. Nonetheless, the observation that the residuals in most of the time series share similar correlation structures suggests that an alternative approach based upon stochastic time-series models may enable us to extract more signal from past data. Predictions based upon these models would then have a smaller envelope of uncertainty. We might then be able to detect smaller changes in the system as they occur.

\section{Cross-correlation}

We have offered potential explanations for the very broad scale differences in the dynamics of southern and northern zooplankton communities but several more detailed patterns remain to be explained: why are the annual Calanus dynamics bimodal in some regions, yet not in others, why are the annual dynamics similar among some (non-adjacent) regions of the North Sea yet different among (some) adjacent boxes. Regional patterns in the hydrographic conditions may be responsible for some of these patterns.

The annual cycle of Calanus numbers appears to be bimodal in boxes 2 and 9 and perhaps also in box 4 . The bimodal pattern of abundance indicates that Calanus in these areas passes through 2 relatively synchronous generations in the year. There is no reason to suspect that Calanus in other parts of the North Sea are incapable of passing through 2 generations in the year so why do we not detect these? As a result of their 
hydrographic conditions, the Calanus populations in boxes 2 and 9 are relatively closed. Consequently, synchrony in population age structure arising out of overwintering patterns will break down only slowly. In contrast, most of the remaining regions of the North Sea are connected to one another by 1 or more current systems. The zooplankton populations in these areas are less isolated from one another, and small variations in the onset of spring growth in different regions, and in local growth rates will rapidly blur the population age structure making it difficult to detect the passage of several generations through the year.

If local zooplankton population dynamics are significantly influenced by import and export of zooplankton then we would expect the dynamics of a down stream box to be related to those of its upstream neighbour. For example, the dynamics in box 3 should resemble those in boxes 10 and 5 , those in box 5 might in turn resemble those in boxes 6 and 7 , and, to a lesser extent, those of box 8 .

The dynamics of copepods in boxes 5 and 3 are indeed similar, as are those of Calanus. On the basis of circulation patterns we would expect those of box 10 to be intermediate but this is not so. The data for box 10 are too sparse to yield unequivocal conclusions, but by most characteristics (long-term mean abundance, amplitude of seasonal cycle, shape of seasonal cycle) the dynamics of box 10 are more similar to those of boxes 6 and 7 than those of boxes 3 and 5. Box 7 lies downstream of box 6 so their similarity is not unexpected, however box 10 lies on the opposite side of the North Sea and is not directly connected to boxes 6 or 7 . It is therefore unclear why these 3 boxes should be similar by so many measures.

Boxes 6 and 8 are also similar by many characteristics yet they are not directly connected and are dominated by very different species of zooplankton. One possible explanation is that both are coastal boxes into which water from outside the North Sea enters directly. Possibly, the transient between 'oceanic' and 'North Sea' dynamic is insensitive to community structure and well represented in these 2 regions.

\section{CONCLUSIONS}

By aggregating the CPR data across space according to hydrographic criteria we hoped to be able to determine the extent to which downstream areas are influenced by their upstream neighbours, i.e. how important is immigration in determining local dynamics? We find that there are few significant cross-correlations at the appropriate time lags $(1$ to $4 \mathrm{mo}$ ). In addition, where there are significant cross-correlations they are sometimes in the 'wrong' direction (the down- stream box leads the upstream box). Thus, in the North Sea it seems that at the spatial scales we are considering, local dynamics are not greatly influenced by immigration/emigration processes. Nonetheless, even after prewhitening of individual time series, significant cross correlations at lag zero often remain. With the possible exception of those areas which are sampled by the same tow route there is no reason to expect the sampling errors in adjacent regions to be correlated. Therefore we suggest that part of the noise remaining after detrending, deseasonalising and prewhitening represents the 'signature' of stochastic events or processes which operate to synchronise local dynamics across large regions.

There is also compelling evidence that local hydrographic conditions play a key role in determining the mean seasonal cycle. The zooplankton communities of areas which share similar hydrographies tend to exhibit similar seasonal dynamics even though the species which compose the community in each area may be very different. This is, perhaps, an argument in favour of the 'functional group' approach which has been adopted in many ecosystem models (Fransz 1981, Ross et al. 1993). This approach is likely to work best in the peripheral areas of the North Sea where the seasonal dynamic is most robust, either because hydrographic forcing is strongest in these regions, or because the zooplankton community is clearly either 'intermediate' or 'neritic' in these regions.

In this paper we have concentrated upon pulling out the deterministic components of copepod and Calanus dynamics. Despite claims that the CPR data are too noisy to yield quantitative information on patterns of numerical change, we have found that up to $70 \%$ of the variance can be explained using a purely deterministic model. This suggests that the signal to noise ratio in the data is much higher than has previously been appreciated. Even after detrending and deseasonalising, the autocorrelation structure in the residuals suggests that there is further (non-time-dependent) signal to be extracted. The structure probably reflects the fact that we are observing an intrinsically autocorrelated process which is subject to random perturbations. Further work will focus upon developing more sophisticated, stochastic models of the data. We hope that these will improve our understanding of the properties of the data, the processes which influence zooplankton dynamics and our ability to detect perturbations to the North Sea's zooplankton in 'real time'.

Acknowledgements. We are pleased to thank the staff of the Sir Alister Hardy Foundation for providing us with the CPR data. Both our analysis of the data and the eventual form of this paper have been greatly influenced by conversations with W. S. C. Gurney, M. R. Heath and S. J. Hay and we 
would like to express our thanks for their contributions. We are aiso grateful for the valuable comments of 2 anonymous referees. This work was funded under the EU Mast 2 program grant number MAS2-CT92-0032-C held by W. S. C. Gurney.

\section{LITERATURE CITED}

Aebischer, N. J., Coulson, J. C., Colebrook, J. M. (1990). Parallel long-term trends across four marine trophic levels and weather. Nature $347 \cdot 753-755$

Backhaus, J. O., Harms, I. H., Krause, M. R. (1994). An hypothesis concerning the space-time succession of Calanus finmarchicus in the northern North Sea. ICES J. mar. Sci. 51: $169-1.80$

Bathmann, U. V., Noji, T T., von Bodungen, B. (1990). Copepod grazing potential in late winter in the Norwegian Sea - a factor in the control of spring phytoplankton growth? Mar. Ecol. Prog. Ser. 60: 225-233

Chambers, J. M., Cleveland, W. S., Kleiner, B., Tukey, P. A. (1983). Graphical methods for data analysis. Wadsworth, Monterey, CA

Colebrook, J. M. (1975). The continuous plankton recorder survey: automatic data processing methods. Bull. mar. Ecol. 8: 123-142

Colebrook, J. M. (1979). Continuous plankton records: seasonal cycles of phytoplankton and copepods in the north Atlantic Ucean and North Sea. Mar. Biol. 51: 23-32

Colebrook, J. M. (1981). Continuous plankton records: persistence in time-series of annual means of abundance of zooplankton. Mar. Biol. 61: 143-149

Colebrook, J. M. (1985a). Continuous plankton records: seasonal variations in the distribution and abundance of plankton in the north Atlantic Ocean and the North Sea. J. Plankton Res. 4(3): 435-462

Colebrook, J. M. (1985b). Continuous plankton records: overwintering and fluctuations in the abundance of zooplankton. Mar. Biol. 84: 261-265

Colebrook, J. M., Taylor, A. H. (1984). Significant time scales of long term variability in the plankton and the environment. Rapp. P.-v. Réun. Cons. int. Explor. Mer 183: 20-26

Dickson, R. R., Kelly, P. M., Colebrook, J. M., Wooster, W. S., Cushing, D. H. (1988). North winds and plankton production in the eastern North Atlantic. J. Plankton Res. 10: $151-169$

Diggle, P. J. (1990). Time series. Clarendon Press, Oxford

Edinburgh Oceanographic Laboratory (1973). Continuous plankton records: a plankton atlas of the North Atlantic and the North Sea. Bull. mar. Ecol. 7: 1-174

Evans, F., Edwards, A. (1993). Changes in the zooplankton community off the coast of Northumberland between 1969 and 1988, with notes on the changes in the phytoplankton and benthos. J. exp. mar. Biol. Ecol. 172: 11-29

Fransz, H. G. (1975). The spring development of calanoid copepod populations in the Dutch coastal waters as related to primary production. In: Persoone, G., Jaspers, E. (eds.) 10th Eur Mar Biol. Symp. Universal Press, Wetteren, p. 247-269

Fransz, H. G. (1981). Carbon dynamics in the food web of the south-eastern North Sea: a simulation study. In: Progress in ecology. Engineering and management by mathematıcal modelling. In: Dubois, D. M. (ed.) Proceedings of the 2nd International Conference on the state-of-the-art in Ecological Modelling. Éditions CEBEDOC Sprl., Liège, p. $701-713$

Fransz, H. G., Colebrook, J. M., Gamble, J. C., Krause, M. (1991). The zooplankton of the North Sea. Neth. J. Sea
Res. 28(1/2): 1-52

Fransz, H. G., Diel, S. (1984). Secondary production of Calanus finmarchicus (Copepods: calanoidea) in a transitional system of the Fladen Ground area (Northern North Sea) during the spring of 1983. In: Gibb, P. E. (ed.) Proc. 19th Eur. Mar. Biol. Symp. Cambridge University Press, Cambridge, p. 123-133

Fransz, H. G., van Arkel, W. G. (1980). Zooplankton activity during and after the phytoplankton spring bloom at the central station of in the FLEX box, northern North Sea, with special reference to the calanoid copepod Calanus finmarchicus (Gunn.). 'Meteor' Forsch. Ergebnisse A22 $113-121$

Green, E. P., Harris, R. P., Duncan, A. (1993). The seasonal abundances of the copepodite stages of Calanus helgolandicus and Pseudocalanus elongatus off Plymouth J. mar, biol. Ass. U.K. 73: 109-122

Hay, S. J., Kiorboe, T., Matthews, A. (1991). Zooplankton biomass and production in the North Sea during the Autumn Circulation Experiment, October 1987-March 1988. Cont. Shelf Res. 11. 1453-1476

Hays, G. C., Carr, M. R., Taylor. A. H. (1994). The relationshin between Gulf Stream position and copepod abundance derived from the continuous plankton recorder survey separating biological signal from sampling noise. J. Plankton Res. 15(12): 1359-1373

ICES (1983). Study Group on Flushing Times of the North Sea, 1983, Coop. Res. Rep. 123. International Council for the Exploration of the Sea, Copenhagen

Lee, A. J., Ramster J. W. (1981). Atlas of the seas around the British Isles. Ministry of Agriculture, Fisheries and Food, Southampton

Miller, C. B., Cowles, T J., Wiebe, P. H., Copley, N. J. Grigg, H. (1991). Phenology in Calanus finmarchicus; hypotheses about control mechanisms. Mar. Ecol. Prog. Ser. 72: 79-81

Rae, K. M. (1952). Continuous plankton records: explanation and methods, 1946-1949. Hull Bull. mar. Ecol. 3: 135-155

Rees, C. B. (1949). Continuous plankton records: the distribution of Calanus finmarchicus and its two forms in the North Sea, 1938-39. Bull. mar. Ecol. 2(14): 215-275

Robinson, G. A., Hunt, H. G. (1985). The Continuous Plankton Recorder Survey: plankton around the British Isles 1982. Ann. Biol. Copenhagen 39: 70-75

Roff, J. C., Middlebrook, K., Evans, F. (1988). Long term variability in the North Sea zooplankton off the Northumberland coast: productivity of small copepods and analysis of trophic interactions. J. mar. biol. Ass. U.K. 68: 143-164

Ross, A. H., Gurney, W. S. C., Heath, M. R., Hay, S. J., Henderson, E. W. (1993). A strategic simulation model of a fjord ecosystem. Limnol. Oceanogr. 38(1) · 128-153

Taylor, A. H., Colebrook, J. M., Stephens, J. A., Baker, N. G. (1992). Latitudinal displacements of the Gulf Stream and the abundance of plankton in the north-east Atlantic J. mar, biol. Ass. U.K. 72: 919-921

Turrell. W. R. (1992). New hypothesis concerning the circulation of the northern North Sea and its relation to the North Sea fish stock recruitment. ICES J. mar. Sci. 49: 107-123

Williams, R. (1985). Vertical distribution of Calanus finmarchicus and $C$. helgolandicus in relation to the development of the seasonal thermocline in the Celtic Sea. Mar. Biol. 86: 145-149

Williams, R., Lindley, J. A. (1980). Plankton of the Fladen Ground during FLEX '76. I. Spring development of the plankton community. Mar. Biol. 57: 73-78

Williams, R., Lindley, J, A., Hunt, H. G., Collins, N. R. (1993). Plankton community structure and geographical distribution. in the North Sea. J. exp. Mar. Biol. Ecol. 172: 143-156 